\title{
Aluminium Alloy-Based Metal Matrix Composites: A Potential Material for Wear Resistant Applications
}

\author{
Rupa Dasgupta \\ CSIR-Advanced Materials and Processes Research Institute (AMPRI), Hoshangabad Road, Madhya Pradesh, Bhopal 462064, India
}

Correspondence should be addressed to Rupa Dasgupta, rupa_dasgupta@rediffmail.com

Received 3 August 2012; Accepted 4 September 2012

Academic Editors: R. Asthana and P. Lukac

Copyright () 2012 Rupa Dasgupta. This is an open access article distributed under the Creative Commons Attribution License, which permits unrestricted use, distribution, and reproduction in any medium, provided the original work is properly cited.

\begin{abstract}
Aluminium alloy-based metal matrix composites (AMMCs) have been by now established themselves as a suitable wear resistant material especially for sliding wear applications. However, in actual practice engineering components usually encounter combination of wear types. An attempt has been made in the present paper to highlight the effect of dispersing $\mathrm{SiC}$ in 2014 base alloy adopting the liquid metallurgy route on different wear modes like sliding, abrasion, erosion, and combinations of wear modes like cavitation erosion, erosion abrasion, sliding abrasion, and the results obtained compared with the base alloy. It is found that there are a number of contributing factors for the resulting wear and all are not necessarily derogatory in nature. The limits within which the AMMCs can exhibit superior performance over the base alloy have been discussed. Worn surface and subsurface studies have been carried out to understand the mechanism of material removal and the role of the different contributing factors to material removal. Wear mechanisms that have been prevalent have been suggested and the possibility of making wear resistant components from the MMCs is discussed based on the experimental results obtained.
\end{abstract}

\section{Introduction}

Material scientists and researchers in this area have been fulfilling the demand of the engineering sector since decades in synthesizing materials to attain the demanded properties to enhance efficiency and cost savings in the manufacturing sector. In fulfilling this demand, a certain trend has been followed, the materials presently been used is tried for improvement through known methods of alloy additions, heat treatment, grain modification, and the like. Once the limit is reached through these methods, either due to economic constraint, difficulty in mass production, or further improvement is ruled out, a different line of thought emerges in further improving the properties or decreasing cost and increasing efficiency. At times, a completely new system takes over, like was done around three decades back when metal matrix composites (MMCs) were thought of. Since a few years, the economically feasible routes, dispersoids, and alloy system that can give meaningful improvement have been narrowed down. Among MMCs, Al-alloy-based composites were always on the forefront of research. Parallel areas of research had then emerged but after about two decades of research in various disciplines to further enhance the properties to satisfy the ever increasing demand of the engineering sector, composites took a lead compared to the other processes when the cost and ease of fabrication were compared. The other methods changed track and chose for themselves different areas of application and Albased metal matrix composites (AMMCs) remained as the most potential candidate to be researched on for making engineering components viable [1-5].

Worldwide research in the area of AMMCs established beyond doubt the advantages of Al-based metal matrix composites (AMMCs) over the base alloy in the laboratory scale. With time, the demands moved ahead and engineering components were demanded from AMMCs. When the industrial application of these were targeted, the question of viability arose and from the different methods adopted for making AMMCs in the laboratory scale, the liquid metallurgy route stood ahead due to its ease of fabrication. Although the other routes were more efficient regarding property attainment and microstructural features, still the ease of fabrication added to the cost economics made the liquid metallurgy route a competitive and viable method 
for bigger sized components. It can be easily concluded from the different results published from across the globe for two decades in the area of AMMCs that the end use needs to be kept in mind before adopting a material and a process of fabrication. This is because the cost factors, ease of fabrication, second phase's nature, shape, size, distribution, wetability between matrix alloy and second phase all have to be considered for making a final choice depending on the component selected, mainly its working conditions for the engineering component to be fabricated.

In the last decade though research continues in this field yet the results obtained were a mere confirmation of the previously attained results, and a plateau in the possible improvement has been reached. Also attempts are being made to make engineering components from the AMMCs but still there is no mass utility of these composites especially those made from the liquid metallurgy route. Some areas where research is still needed before these versatile materials see the light of the day as engineering components include machining, joining, repeatability of properties on mass production, and effect of secondary processing. The difficulty in meeting the industry's demand can be easily seen from the lesser number of research publications since the millennium, and old researchers were finding it difficult to answer questions related to the engineering potential of these composites. The material with better property needs to be converted to a component with better properties than presently available and here lies the challenge, like (i) cast AMMCs will seldom find use as engineering components, (ii) advantages accrued in cast composites do not always hold good when processed, (iii) moreover secondary processing of composites has its own set of challenges, and (iv) only selected alloying elements and second phase dispersions can withstand the rigours and give meaningful results.

To date, the literature at least does not pose a very rosy picture regarding availability of engineering components been used which are made from AMMCs. Maybe this would need a few years more, or may be since the development of engineering components is difficult to publish, the details are not openly available. However, a few components that have seen the light of the day from AMMCs include Swash plate, tennis racket, transfer bench, foot rest, and a few automobile components like brake drum, casings, head light combos, mining equipments, and a few components for structural applications, with an intention to replace either cast iron products or Al-alloy products presently used especially aimed at weight reduction, strength, stiffness, and energy efficiency. However, the aerospace industries, automobile and railway sectors are keenly observing the composite research development.

The enormous amount of $\mathrm{R} \& \mathrm{D}$ that has gone into Al-based MMCs of every possible alloy with different dispersoids establishing beyond doubt the usefulness of making composites but a choice has to be made with both the base alloy selection and dispersoid size and volume percentage for making engineering components. Another point is that all engineering components will undergo somewear related degradation with use even in an otherwise nonwear environment. The $\mathrm{Al}-\mathrm{Cu}$ and $\mathrm{Al}-\mathrm{Zn}$-based alloys are commonly used for making engineering components used in environments like those mentioned above.

Literature review of Al-Cu-based composites show that this system has been widely investigated both in terms of understanding the mechanism of formation and property evaluation of composites [6-8]; the main dispersoids being $\mathrm{SiC}$ and $\mathrm{Al}_{2} \mathrm{O}_{3}$. Although investigations with varying volume fraction of dispersoids have been done, meaningful results have been obtained when the dispersoid percentage has been restricted to 15. Again the size of the dispersoids is dependent on/or restricted to the processing route adopted. The Al-Cu-based MMCs have been evaluated for their sliding, and abrasive wear properties in most cases have reported improvement in the wear resistance of composites over the control alloy; however, the degree of improvement depends to a large extent on the experimental conditions and microstructure of the MMCs. In some cases, however the wear resistance of MMCs was found to be inferior to the alloy; this could be correlated to extreme experimental conditions or improper formation of composites leading to detachment of the dispersoids. The wear resistance of MMCs indicated that both the reinforcement size and matrix strengthening have a significant effect on the wear properties of the composites. Sliding wear resistance of the composites increases with increasing $\mathrm{SiC}$ particulate size. For the composite containing various particulate sizes, the wear properties of the composites cannot be directly correlated to the bulk hardness (HRB) of the composites. Under lubricated conditions (paraffin oil) the wear rates were about $1 / 10$ those under dry conditions. Wear mechanism has been explained on the nature of wear debris, wear cracks, its growth, propagation, and detachment. These are the factors which contribute to wear loss. No direct relationship has been found between hardness and wear resistance. Maximum wear resistance has been reported after over ageing [9-12]. The improvement of sliding wear resistance of particulate MMCs over the control alloy is more evident at lower sliding speeds; at higher speeds the wear rate increases which is in contrast to the control alloy which shows better wear resistance (i.e., lower wear rate) at higher speeds. However the seizure pressure of composites is better than the control alloy as reported by several investigators. Reports indicate that the wear resistance of composites increases with increasing volume fraction and size of the particulates. The excellent wear resistance of the composites is mainly attributed to the effective resistance of the SiC particle to penetration, grinding, and cutting by the ceramic slider. The effect of $\mathrm{SiC}$ size is greater than that of volume fraction. The improvement in the wear resistance of composites containing small particles over the unreinforced alloy is attributed to matrix strengthening of the particles as well as wear resistance of the particles, whereas the higher wear resistance of the composites containing large particles compared with those containing small particles is mainly accounted for by the excellent wear resistance of the large $\mathrm{SiC}$ particles. Abrasive wear tests have been carried out by investigators under high stress conditions. In general, wear rate of composites are less than the control alloy. The nature of variation with load, however, remained the same for the 
control alloy and composite [13-15]. The nature and volume of material removal are controlled by factors like dispersoid size, penetration depth (dependent on load), size of abrasive particles, work hardening of the subsurface (matrix) regions, microcracking tendency of material, reduction in cutting efficiency of the abrasive, blunting of abrasives, fragmentation, and so forth. Detailed investigations have demonstrated an increase in wear resistance with increasing volume fraction of particulates (at constant particle size) and also with increasing particle size (with constant volume fraction).

The present paper details highlights the effect of dispersing $\mathrm{SiC}$ in different alloy matrices adopting the liquid metallurgy route on different wear modes normally encountered in non wear/mild environments by engineering components like sliding, abrasion, combinations of slidingabrasion, and the results obtained compared with the base alloy. It is found that there are a number of contributing factors for the resulting wear and all are not necessarily derogatory in nature. The limits within which the AMMCs can exhibit superior performance over the base alloy have been discussed. Worn surface and subsurface studies have been carried out to understand the mechanism of material removal and the role of the different contributing factors to material removal. Wear mechanisms that have been prevalent have been suggested and the possibility of making wear resistant components from the MMCs is discussed based on the experimental results obtained.

\section{Experimental Details}

2.1. Synthesis of Composites. The composites used in the present study were prepared by the liquid metallurgy technique. For preparing the composites, constituents in appropriate proportions conforming to 2014 and 7075 alloy system consisting of Al-4.4 Cu-0.5 Mg-0.8 Si-0.8 Mn and 1.6 $\mathrm{Cu}, 2.5 \mathrm{Mg}, 5.6 \mathrm{Zn}, 0.3 \mathrm{Cr}$, respectively, were melted in a gasfired furnace in a graphite crucible. Weighed and preheated dispersoids of size between 15 and $20 \mu \mathrm{m}$ and 10 weight $\%$ as optimized earlier [16] was poured into the melt after passing through a sieve. During insertion of the dispersoid, the melt was stirred constantly by means of a stirrer placed in the melt operated by a motor. The stirrer speed was controlled as required. After complete insertion of the dispersoids in the molten alloy, the alloy was simultaneously stirred and heated for some time for uniform mixing and temperature. The melt with the dispersoids were then poured into preheated permanent moulds of required size and shape. The chemical composition of the alloy was analysed using SPARKMET optical spectrometer (Model: SPECTRA) for confirmation.

2.2. Ageing and Tempering. In the case of 2014 alloy system, it was found that the optimised ageing conditions are different for the alloy and composite. The composite attains peak hardness at $180^{\circ} \mathrm{C}$ compared to $210^{\circ} \mathrm{C}$ for the alloy [17].

The alloys and composites of 7075 system were aged under $\mathrm{T} 6$ tempering and adopting retrogression and reageing
TABLE 1: Conditions and hardness of alloys and composites tested for sliding wear behaviour.

\begin{tabular}{lcc}
\hline Sample & Condition & Hardness (HB) \\
\hline 2014 Alloy system & As cast & $86.6 \pm 6$ \\
Alloy & Aged at $210^{\circ} \mathrm{C}$ for 3 hours & $114.2 \pm 4$ \\
Alloy & Aged at $240^{\circ} \mathrm{C}$ for 3 hours & $109.4 \pm 3$ \\
Alloy & As cast & $83.4 \pm 2$ \\
Composite & Aged at $180^{\circ} \mathrm{C}$ for 3 hours & $124.2 \pm 7$ \\
Composite & As cast & \\
\hline 7075 Alloy system & T6 ageing condition & $137.6 \pm 4$ \\
Alloy & Retrogressed and reaged & $71.0 \pm 3$ \\
Alloy & As cast & $101.2 \pm 4$ \\
Alloy & T6 ageing condition & $99.2 \pm 3$ \\
Composite & Retrogressed and reaged & $72.1 \pm 3$ \\
Composite & & \\
Composite &
\end{tabular}

TABLE 2: Tensile properties of alloys and composites.

\begin{tabular}{lcc}
\hline System & Condition & UTS, MPa \\
\hline \multirow{2}{*}{2014 Alloy } & Cast & 176 \\
& Aged under optimized condition & 259 \\
\hline \multirow{2}{*}{ 2014 Composite } & Cast & 93 \\
& Aged under optimized condition & 170 \\
\hline \multirow{2}{*}{7075 Alloy } & Cast & 87 \\
& Aged under optimized condition & 158 \\
\hline \multirow{2}{*}{7075 Composite } & Cast & 63 \\
& Aged under optimized condition & 112 \\
\hline
\end{tabular}

method (RRA). In the RRA method, the samples were quenched and aged as per the following steps [18].

(i) The alloys and composites were aged at $490^{\circ} \mathrm{C}$ for 8 hours and water quenched. The quenched samples were heat treated at $120^{\circ} \mathrm{C}$ for 24 hours and were furnace cooled. This corresponds to T6 ageing.

(ii) The $\mathrm{T} 6$ aged samples were retrogressed at $200^{\circ} \mathrm{C}$ for 45 minutes.

(iii) The retrogressed samples were reaged at $120^{\circ} \mathrm{C}$ for 24 hours.

2.3. Test Specimens. The ageing conditions which exhibited maximum hardness were used for studying the microstructure, sliding and two body abrasive wear behaviour are given in (Table 1).

2.4. Microstructure. Samples around $20 \mathrm{~mm}$ diameter cut from the cast and aged specimens were metallographically polishing and etching in Kellar's reagent for metallographic studies. The microstructures were observed in the optical microscope and/or JEOL scanning electron microscope operating at $20 \mathrm{kV}$ in both the secondary mode of electron transmission and the back scattered electron emission mode, although the features observed were the same in both modes of electron emission, in some cases where the 
secondary mode of electron emission could not resolve the microconstituents properly, the features observed in the back scattered electron emission mode have been reported.

2.5. Sliding Wear Test. Dry sliding wear tests were carried out on a pin-on-disc wear testing machine in which the specimen was held against a rotating steel disc and this sliding motion results in wear of the pin. The weight of the specimen was taken after every $500 \mathrm{~m}$, sliding distance. The weight loss was calculated from the difference in weight between the initial weight and weight after a specified number of rotations. The volume loss calculated by dividing the weight loss by the density of the material (calculated by Archimedes' principle) or the wear rate calculated by dividing the volume loss by the total distance traversed is used for comparison between the different conditions. Experiments were carried out at two loads of 1 and $3 \mathrm{MPa}$ and at two speeds of rotation corresponding to 200 and $750 \mathrm{rpm}$ up to sliding distance of $2500 \mathrm{~m}$. Weight loss measurements were taken after every $500 \mathrm{~m}$ sliding distance approximately. The weight loss was divided by the density of the sample to obtain the volume loss. Volume loss divided by the actual distance traversed was used to determine the wear rate of the sample. The volume loss $\left(\mathrm{m}^{3}\right)$ was used to compare the wear behaviour of the alloy and composites. The sliding wear properties of the alloys and composites were determined under dry sliding conditions for comparison of properties between the alloys and composites in the cast and aged conditions under similar experimental conditions.

2.6. High Stress Abrasive Test. High-stress (Two Body) abrasive wear tests were carried out using a Suga make abrasion tester (Model: NUS 1, Japan). Rectangular shaped specimens having dimensions $40 \times 35 \times 4 \mathrm{~mm}$ (thickness) were cut from the alloys and composites cast in discs of $70 \mathrm{~mm}$ diameter and $6 \mathrm{~mm}$ thickness, and ground to obtain a smooth surface before carrying out the tests. Emery paper embedded with the desired size of SiC particles was used as abrasive medium. The emery paper was fixed on rotating wheel (diameter of the wheel is $50 \mathrm{~mm}$ and thickness is $12 \mathrm{~mm}$ ). The specimen was fixed with a locking arrangement against the abrasive medium. Load was applied on the specimen with a cantilever mechanism. The sample was made to slide over the abrasive paper fixed on the rotating wheel. The abrasive changed its position after each stroke corresponding to a sliding distance of $0.065 \mathrm{~m}$. Weight loss of the specimen was measured after it completed 400 strokes, that is, corresponding to a sliding distance of $26 \mathrm{~m}$. A Mettler make microbalance was used for weighing the specimens. The specimen was cleaned with acetone prior to and after the wear test. Fresh abrasive paper was used after every 400 strokes. Tests were carried out up to a distance of $260 \mathrm{~m}$. Loads applied were 3 and $5 \mathrm{~N}$ with the abrasive size of 220 grit. The weight loss was obtained from the difference in weight of the sample before and after the test after every $26 \mathrm{~m}$ sliding distance. The volume loss and wear rate attained (calculated as mentioned before) were used to compare the attained properties.
The same set of samples, as for sliding wear tests mentioned above, were tested for their abrasive wear behaviour.

2.7. Worn Surface Studies. The worn surface and subsurface was studied under the scanning electron microscope (SEM) to understand the nature of material removal and surface damage and to compare between material removal mechanism between the different types of wear and also between the different conditions and the effect of dispersoid addition if any on the mechanism of material removal.

\section{Results}

3.1. Microstructural Features. In the back scattered electron image of the as cast 2014 alloy (Figure 1(a)) clear grain boundaries are observed with some precipitation in them. The important micro constituents of the cast structure correspond to primary $\alpha$-dendrites surrounded by eutectic $\alpha-\mathrm{CuAl}_{2}$ (marked A \& B resp. in Figure 1(a)). The main features on solutionising and ageing under optimised conditions are fine precipitates along the grain boundaries which grow from discontinuous to continuous precipitates without coarsening (Figure 1(b)). At longer duration of time there is also coarsening at lower ageing temperatures (Figure 1(c)). The back scattered electron image of the cast composite show a near uniform distribution of the $\mathrm{SiC}$ particulates (Figure 2(a)). A good bonding between the alloy and particulate is also observed. The microstructural features observed are definite grain boundaries that are more continuous as compared to the alloys and the aged composites (Figure 2(b)) show similar features as the aged alloy.

In the as cast state, the 7075 alloy shows heterogeneous precipitation along the grain boundaries as well as inside the grain boundaries (Figure 3(a)). The alloy exhibits a black filigree of $\mathrm{MgZn}$. Under RRA conditions dissolution of grain boundaries was observed (Figure 3(b)) and showed a granular structure with grains of varying size and distribution of very fine phases in the grains in the Al-matrix resulting from nonuniform solidification rates during casting. The cast composite exhibits (Figure 3(c)) a near uniform distribution of the particulates within the matrix and clear dendrites are seen in the matrix of Aluminium; grain boundaries are clearly defined with some precipitates in the grains. On ageing, dissolution of grain boundaries was observed together with coagulation of precipitates around the $\mathrm{SiC}$ dispersoids (Figure 3(d)).

3.2. Sliding Wear Behaviour. In order to compare the behaviour between the alloy and compositefor aparticular experimental condition, the volume loss against sliding distanceis plotted as in Figures 4-18. A general observation for both the alloy systems both the composite and alloy in the cast and aged conditions, the alloy samples seized at the load of $3 \mathrm{MPa}$ before traversing any meaningful distance; other experimental factors, namely, the speed of rotation and sliding distance did not report seizure for any specimen condition till the limit of the tests, namely, $750 \mathrm{rpm}$ speed 


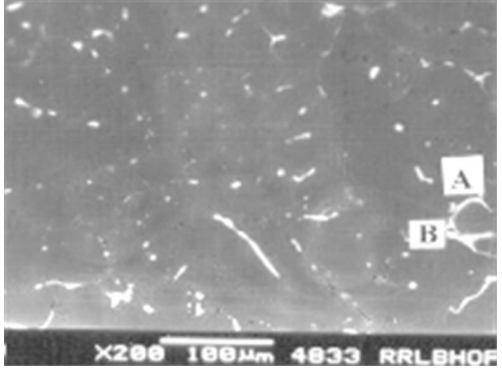

(a)

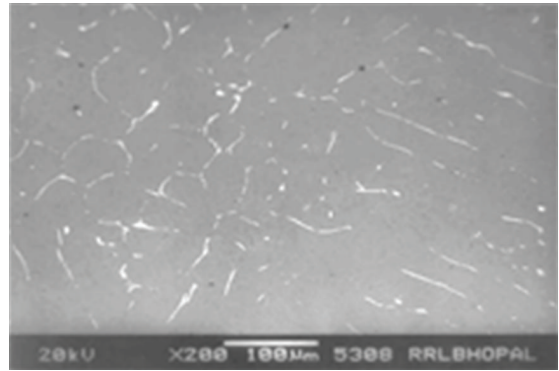

(b)

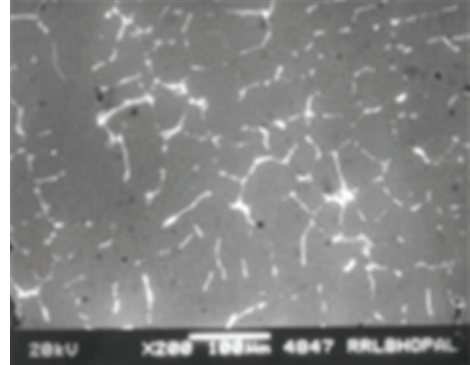

(c)

FIGURE 1: SEM photographs of alloy. (a) As cast alloy (b) under optimised ageing conditions (c) aged alloy at longer duration exhibiting coarsening.

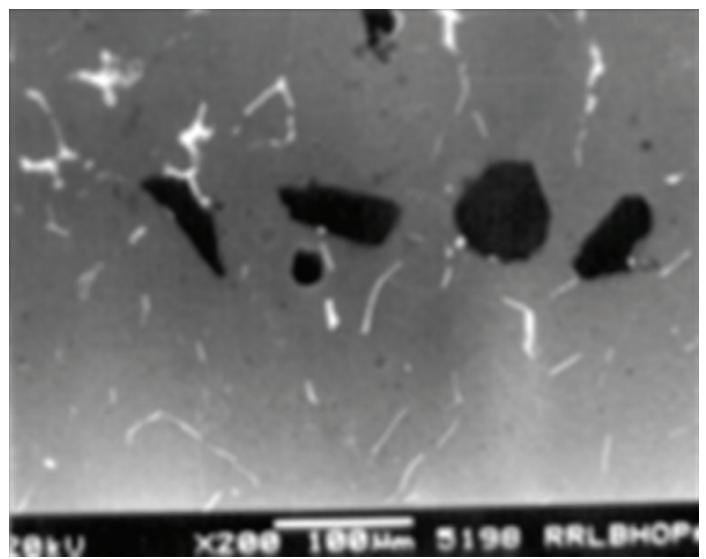

(a)

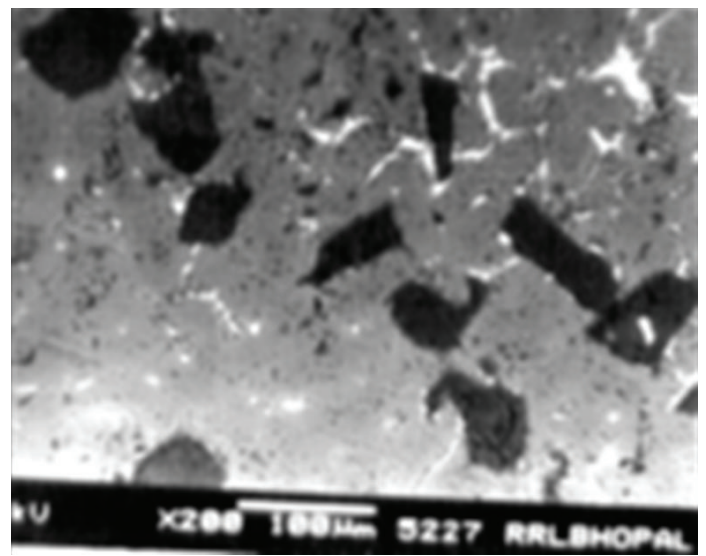

(b)

FIGURE 2: SEM photographs of composite. (a) As cast (b) under optimised ageing conditions.

and $2500 \mathrm{~m}$ sliding distance. However, the composite made with 7075 alloy both in the cast and aged conditions can withstand the pressure of $3 \mathrm{MPa}$ till completion of the tests.

Again making composites reduces the volume loss in all the cases as compared to their alloy counterparts. Beneficial effect of ageing is more pronounced in the 2014 alloy system (Figure 4). Increases speed decreases wear rate probably due

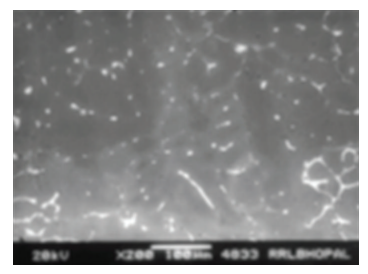

(a)

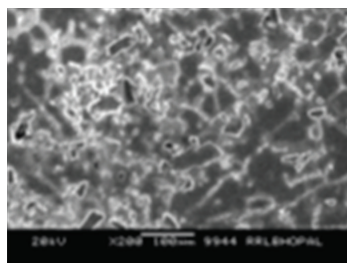

(c)

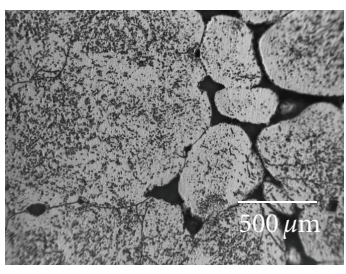

(b)

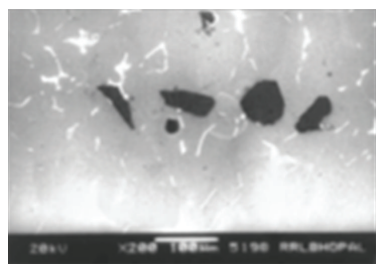

(d)
Figure 3: Microstructures of 7075 alloy. (a) Cast alloy (b) aged alloy (c) cast composite (d) aged composite.

to the less time of contact, this is reflected in the worn surface's degradation also in the form of shallow ridges.

Ageing improves the wear rate in both the alloy and composite of the 2014 system, this can be attributed to the strengthening attained on ageing (Table 2 showing improved UTS). In some cases, the wear rate (calculated as volume loss divided by the actual sliding distance traversed) increases at longer sliding distance, which could be due to softening of the matrix on prolonged exposures.

The behaviour of volume loss as a function of the sliding distance for the 7075 system under the different experimental conditions for the cast and aged condition is plotted in Figure 5. It is observed that ageing improves the wear resistance inverse of volume loss significantly in the case of composite; for alloys there is no appreciable effect (Figures $5(\mathrm{a})$ and 5(b)). However the effect is most pronounced in both the alloy and composite when tested at higher load of $3 \mathrm{MPa}$.

Increasing speed of rotation decreases the volume loss for both the alloy and composite (Figure 6(a)); its effect is more pronounced than the effect of load (Figure 6). 


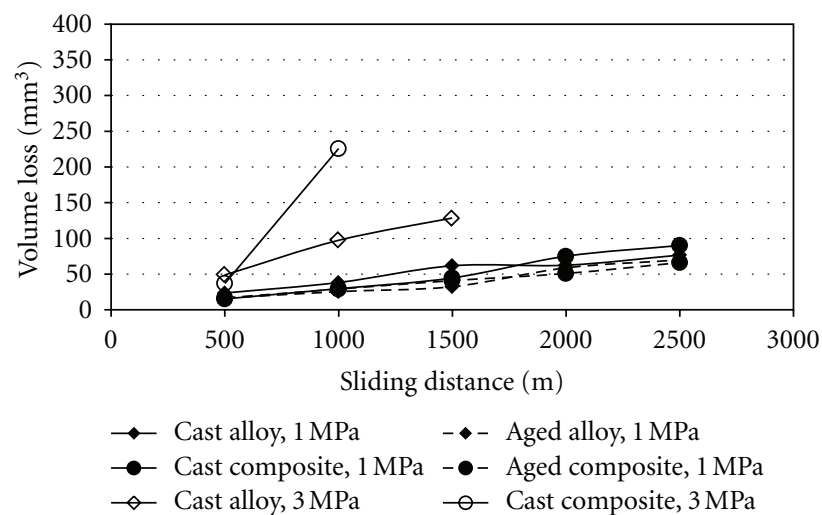

(a)

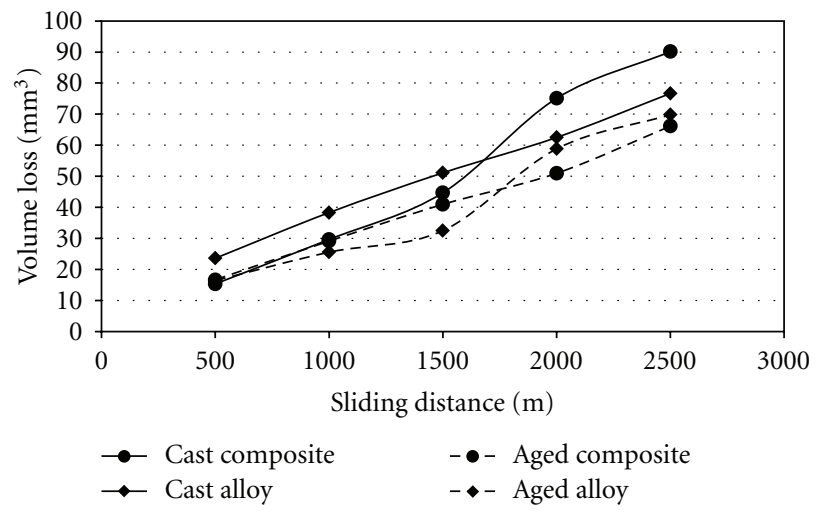

(b)

FIGURE 4: Sliding wear of 2014 alloy and composite at (a) $200 \mathrm{rpm}$ (b) $750 \mathrm{rpm}$.

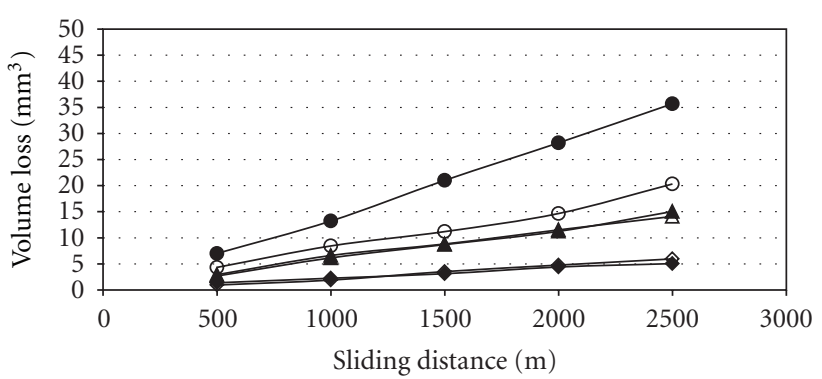

$\multimap 1 \mathrm{MPa}, 750 \mathrm{rpm}$ alloy, cast $\multimap 1 \mathrm{MPa}, 750 \mathrm{rpm}$ alloy, RRA

$\neg 1 \mathrm{MPa}, 200 \mathrm{rpm}$ alloy, cast $\triangle 1 \mathrm{MPa}, 200 \mathrm{rpm}$ alloy, RRA

$\rightarrow 3 \mathrm{MPa}, 200 \mathrm{rpm}$ alloy, cast $\rightarrow 3 \mathrm{MPa}, 200 \mathrm{rpm}$ alloy, RRA

(a)

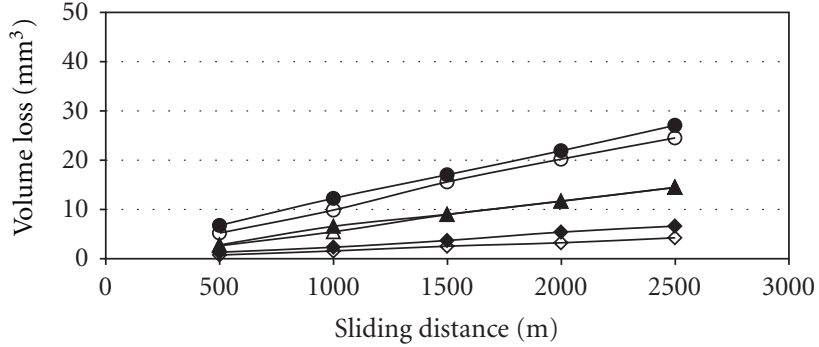

$\longrightarrow 1 \mathrm{MPa}, 750 \mathrm{rpm}$ composite, cast

$\rightarrow 1 \mathrm{MPa}, 200 \mathrm{rpm}$ composite, cast

$\rightarrow 3 \mathrm{MPa}, 200 \mathrm{rpm}$ composite, cast

$\leadsto 1 \mathrm{MPa}, 750 \mathrm{rpm}$ composite, RRA

$\triangle 1 \mathrm{MPa}, 200 \mathrm{rpm}$ composite, RRA

- $3 \mathrm{MPa}, 200 \mathrm{rpm}$ composite, RRA

(b)

FIGURE 5: Effect of ageing on the sliding wear behaviour of 7075 alloy and composite (a) alloy and (b) composite.
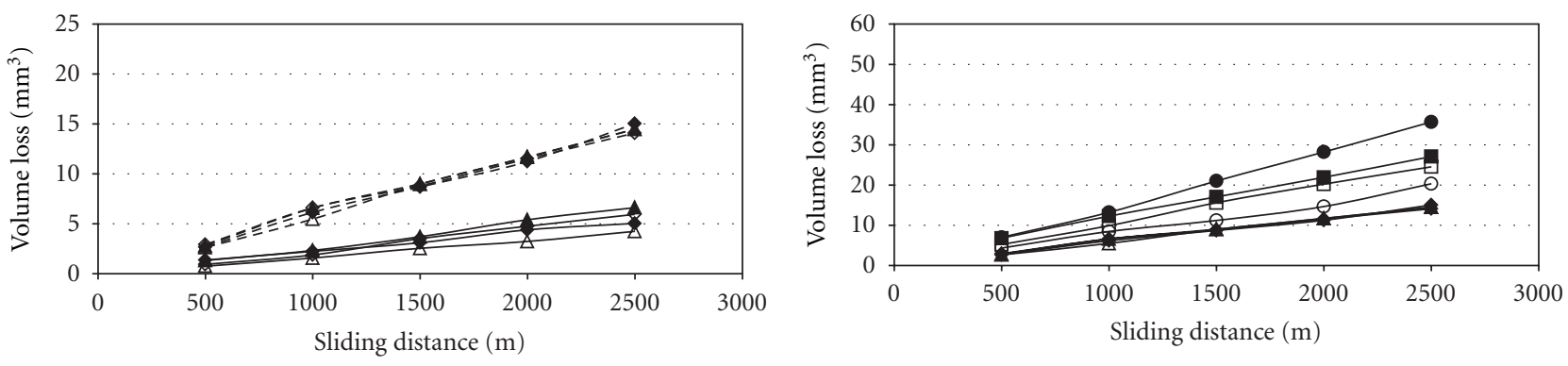

$\rightarrow 1 \mathrm{MPa}, 750 \mathrm{rpm}$ alloy, cast

$\rightarrow 1 \mathrm{MPa}, 750 \mathrm{rpm}$ composite, cast

- $1 \mathrm{MPa}, 200 \mathrm{rpm}$ alloy, cast

- $1 \mathrm{MPa}, 200 \mathrm{rpm}$ composite, cast

$\multimap 1 \mathrm{MPa}, 750 \mathrm{rpm}$ alloy, RRA

$\triangle 1 \mathrm{MPa}, 750 \mathrm{rpm}$ composite, RRA

$-\diamond-1 \mathrm{MPa}, 200 \mathrm{rpm}$ alloy, RRA

- $A-1 \mathrm{MPa}, 200 \mathrm{rpm}$ composite, RRA

(a)

(b)

FIGURE 6: Effect of experimental parameters on the sliding wear behaviour of 7075 alloy and composite (a) at different speeds of rotation and (b) at different loads. 


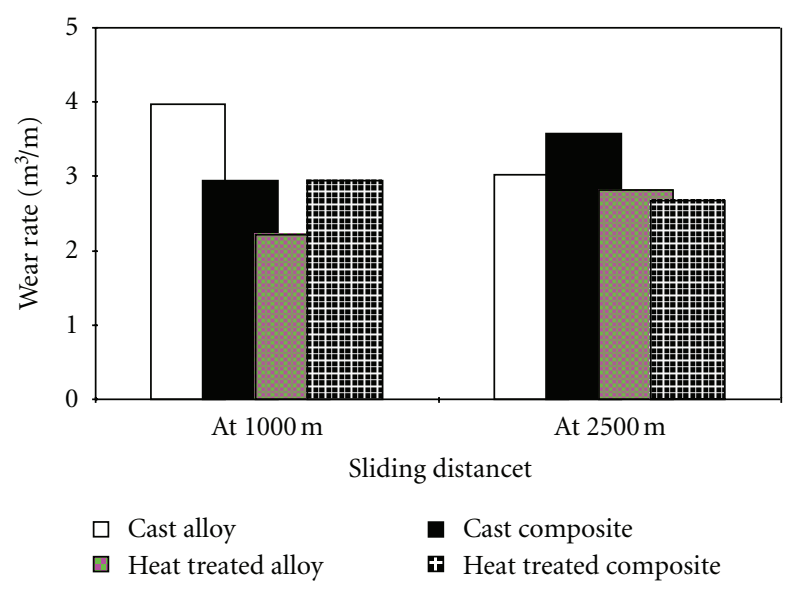

FIGURE 7: Sliding wear behaviour of 2014 alloy and composite at $750 \mathrm{rpm}$ sliding speed and load of $1 \mathrm{MPa}$.

Moreover, ageing of alloy or composite in the case of 7075 system does not have any significant bearing in reducing the volume loss and this is probably due to softening of the matrix as a result of homogenisation and volume loss is directly dependant on the hardness and stiffness of the material. In this alloy system like in the case of 2014 system, it is interesting to note that higher speeds of rotation results in lesser volume loss which is probably due to less time that the surfaces get to slide against each other due to the enhanced speed; the material damage is also less in such cases as seen from comparing its worn surfaces at a particular load at different speeds.

The final wear rate for the samples after completion of the tests shows significant decrease at higher speeds for both the cast and aged conditions of the composites as compared to the base alloy (Figures 7 and 8 ). This is to say that if these composites were used for making engineering components, they would perform better at higher speeds and lower loads than at other combinations.

3.3. Worn Surface Studies. The worn surface features are in accordance with the material loss observed. The SEM photographs exhibit the features and give a relative idea of the damage due to sliding wear. The depth of the wear grooves is also a measure of the material loss. The worn surface of both the alloy systems is similar. Those for 2014 are reported here. In the cast condition at a load of $1 \mathrm{MPa}$ (Figure 9(a)) is characterised by large, continuous dimples and uniform wear tracks; at higher sliding distances breaking of the surface is also observed, suggestive of brittle nature of the alloy and its inability to withstand long sliding distance. The worn surface at a load of $3 \mathrm{MPa}$ is suggestive of seizure (Figure 9(b)) with severe metal flow. In the aged alloy, the worn surface at $1 \mathrm{MPa}$ load is characterized by uniform wear tracks and small dimples (Figure 9(c)).

The worn surface of the composite under cast and aged conditions is shown in Figure 9. The worn surface of the cast alloy (Figure 10(a)) is characterized by continuous wear grooves and discontinuously scattered small dimples. This

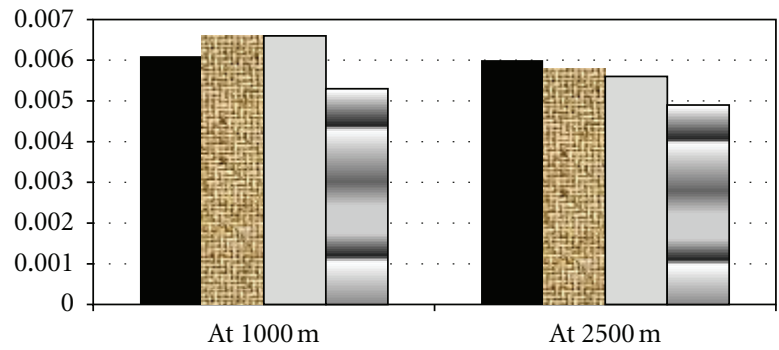

(a)

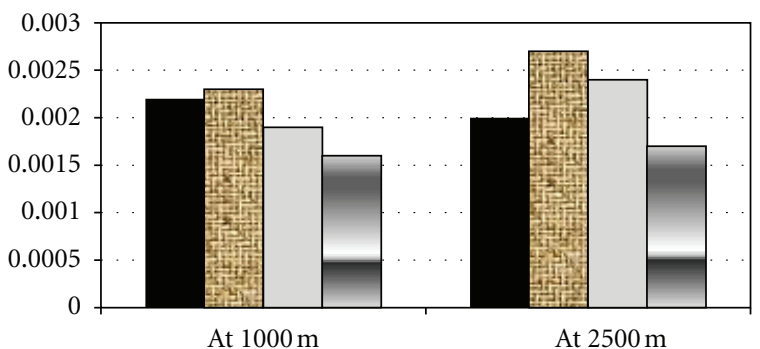

(b)

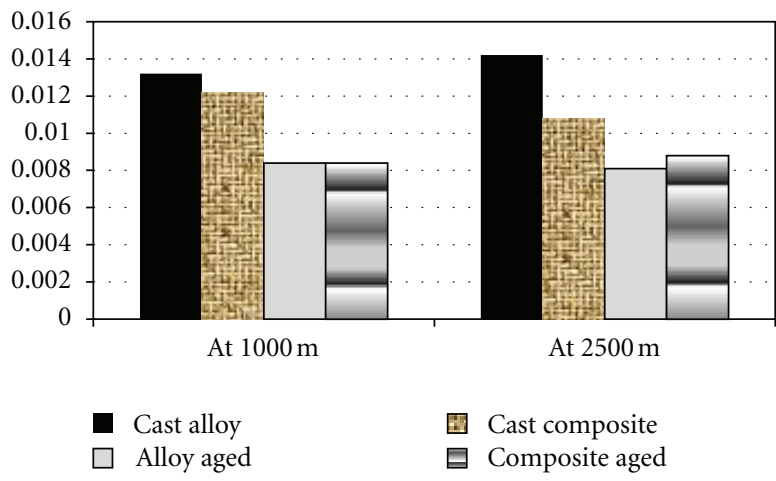

(c)

FIgURE 8: Wear rate variation for 2014 alloy and composite at sliding distance 1000 at and $2500 \mathrm{~m}$ (a) $200 \mathrm{rpm}, 1 \mathrm{MPa}$ and (b) $750 \mathrm{rpm}, 1 \mathrm{MPa}$ (c) $200 \mathrm{rpm}, 3 \mathrm{MPa}$.

mechanism of material removal in the case of composite appears to be from the surface only, whereas for the alloy under similar experimental conditions removal is from beneath the sample surface. The cast composite is shown to suffer maximum material loss at times (Figure 10(b)) by peeling off of the dispersoids resulting in sudden weight (volume) loss. The worn surface of the aged composite does not show very clear wear tracks (Figure 10(c)) and is characterized by small dimples and pitting indicating less material loss and damage.

The worn surface shows only shallow wear tracks under high speeds of rotation (sliding speed) as compared with the slower speed at the same load for the alloy (Figures 11(a) and 11(b)). The worn tracks are deeper when the pressure is high, the damaged surface is characterized by deep wear grooves and material removal is through micro ploughing. The depth of the grooves is indicative of the quantity of material removal. Deeper wear grooves are characteristics 


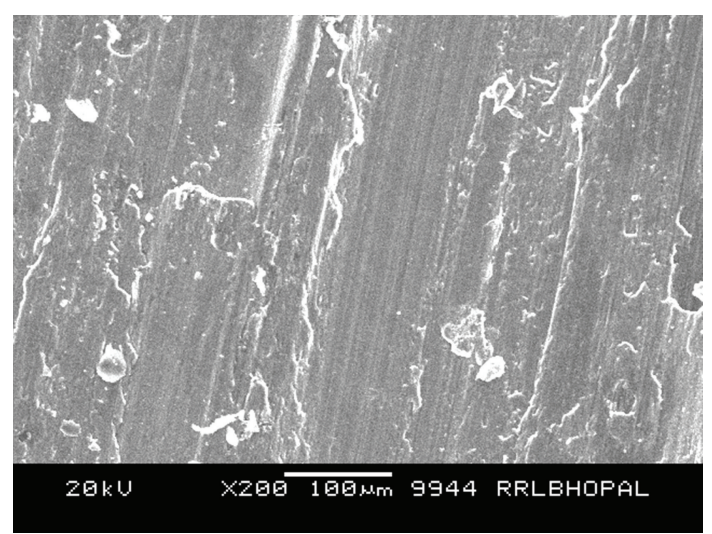

(a)

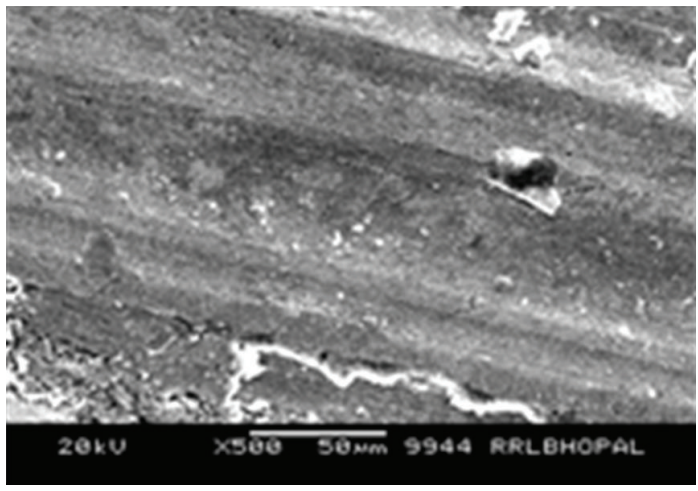

(c)

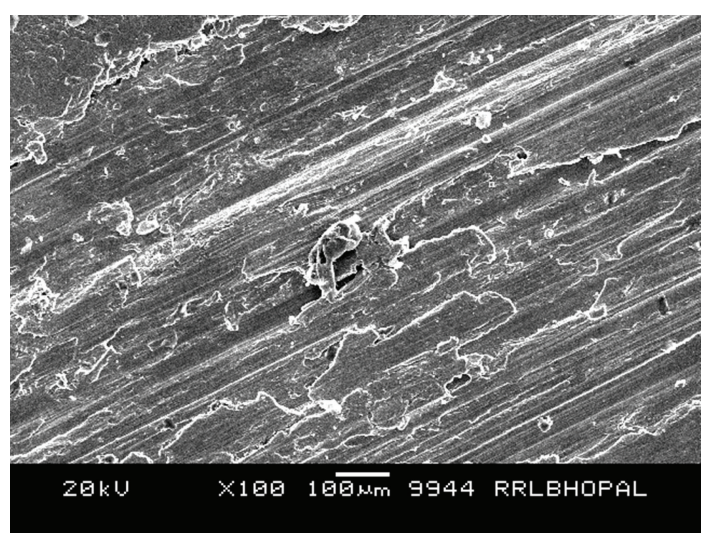

(b)

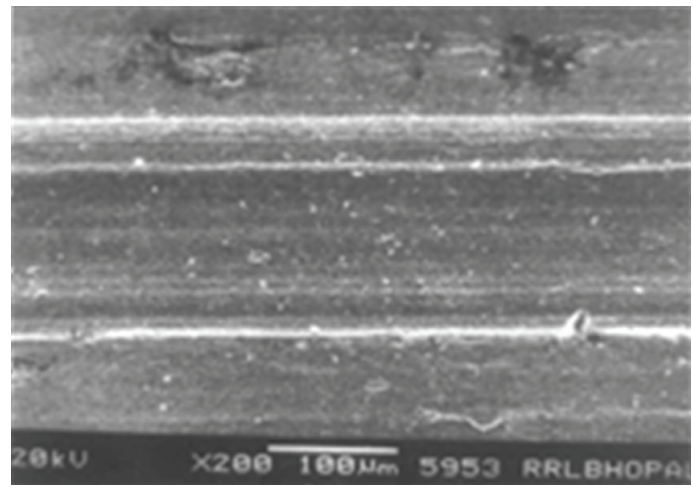

(d)

Figure 9: Worn surface of alloy. (a) at a pressure of $1 \mathrm{MPa}$ at $200 \mathrm{rpm}$ (b) at $3 \mathrm{MPa}$ suggestive of seizure (c) aged alloy (d) at higher speeds showing less damage.

of material removal of micro ploughing, whereas material removal by oxidation of the surface is the cause for material removal from the surface only.

Seizure of the material can be understood from the machine stopping and also from the surface being tested which shows material movement; the scanning electron micrographs of seized samples (Figure 12) shows complete overlapping of material and material movement cutting across wear tracks (Figure 12(a)); the seized material in turn does not show any structure and looks like a lump of mass on the surface adhered to the surface and material from the inner surface are also exposed (Figure 12(b)).

The resistance offered by the $\mathrm{SiC}$ particulates influences sliding wear resistance of the composites. It is interesting to note that the wear rate or (volume loss) variation with hardness is different for the alloy and composite. A direct proportionality between hardness and wear rate would be increase in hardness resulting in decrease wear rate. Contrary to this, in the case of composite (for all conditions of experimental factors and material conditions) for increase in hardness there is an increase in wear rate; however in the case of alloy, wear rate decreases with increase in hardness. This behaviour is probably due to the fact that the soft surface can accommodate larger damage during sliding than harder samples which trend to be brittle resulting in more material loss. Addition of $\mathrm{SiC}$ to form composites increases brittleness of the alloy, hence the variation between wear rate and hardness are different for the alloy and composite. Higher material loss is reported for composites when the $\mathrm{SiC}$ particulates are removed due to sliding, prevalent under conditions of high pressure and low sliding speeds (Figures 9 (b) and 10(b)). Under high speeds of sliding, no damage is seen of the SiC particulates (Figure 9(d)) and lower material loss (volume loss) is reported; the wear mechanism is similar to that of the alloy under same experimental conditions, that is, from the surface only.

3.4. High Stress Abrasive Wear Behaviour. The high stress abrasive wear properties of alloys and composites of the 2014 system in the cast and heat treated under optimised conditions reveal the effectiveness of both heat treatment and formation of composite (Figure 13). The aged samples exhibit lower wear rate (improved wear resistance) as compared to the cast counterparts under identical experimental conditions. Again the composites in both the aged and cast condition exhibit significantly reduced wear rates (which would result in much superior wear performance) over the counterpart alloys under similar experimental conditions. Higher loads as is expected resulted in higher wear rates. It 


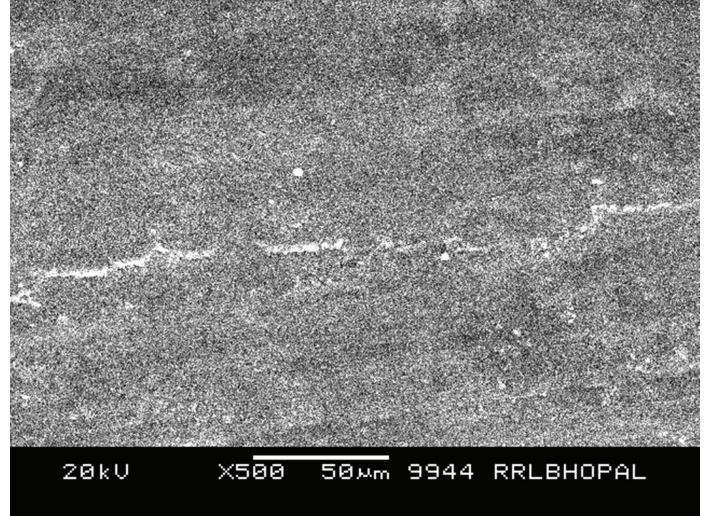

(a)

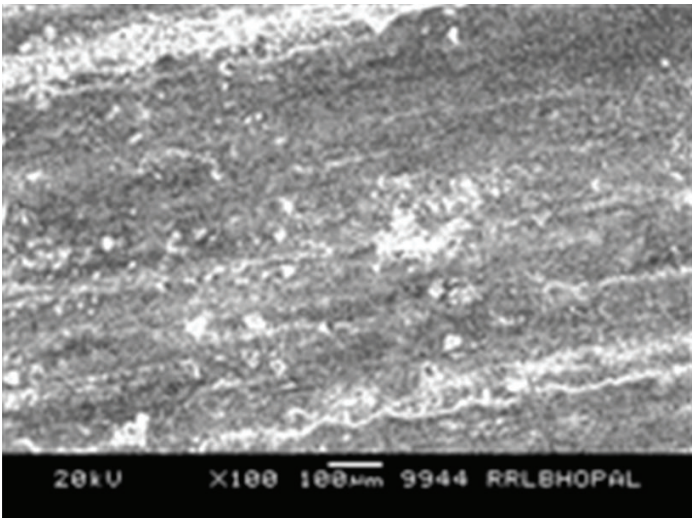

(c)

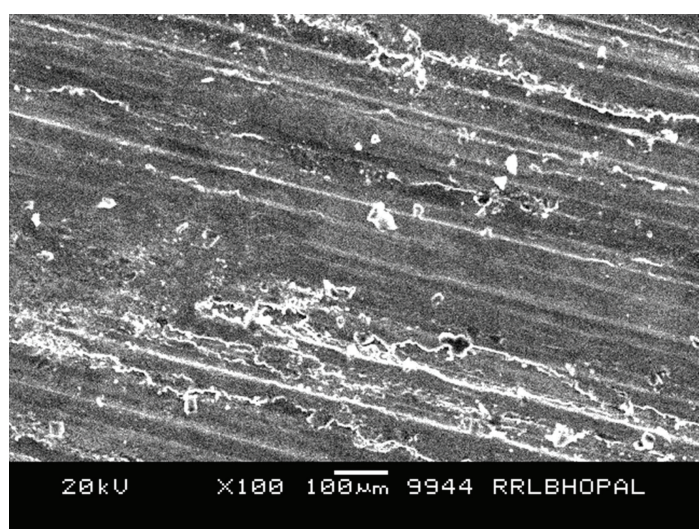

(b)

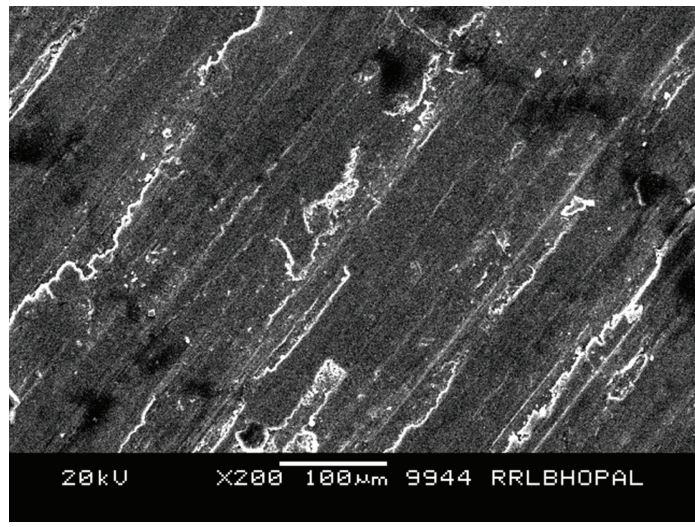

(d)

FIgURE 10: Worn surface of composite. (a) Cast at a pressure of $1 \mathrm{MPa}$ at $200 \mathrm{rpm}$ (b) peeling off of the dispersoids resulting in sudden weight loss at high loads (c) aged composite do not show very clear wear tracks (d) at higher pressures.

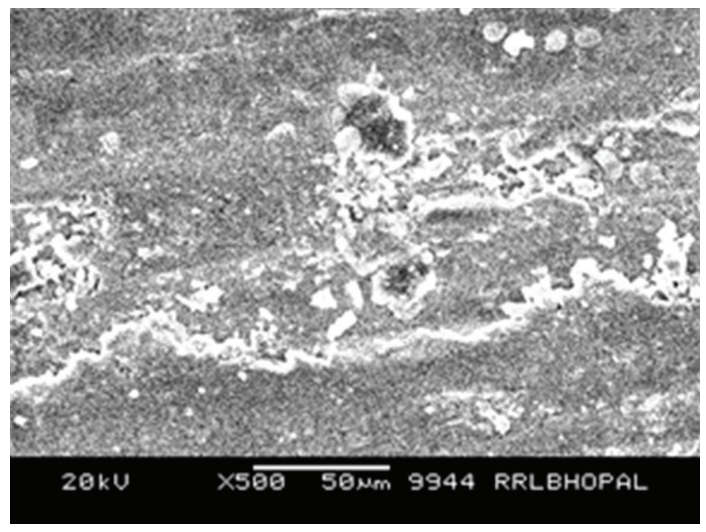

(a)

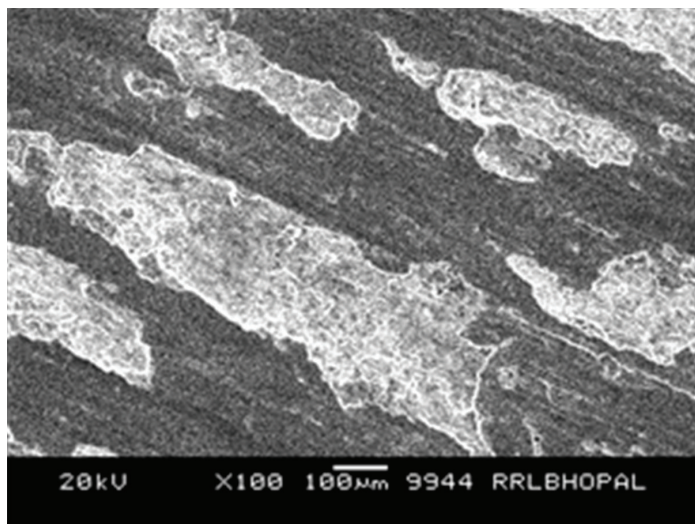

(b)

Figure 11: Increase in depth of wear tracks with pressure (a) at $1 \mathrm{MPa}$ (b) at $3 \mathrm{MPa}$.

can be undoubtedly be said that the composites from these alloys would perform much better than the alloys where there is a demand of superior abrasive wear resistance. The improved wear resistance of the composites is attributed to the resistance offered by the $\mathrm{SiC}$ dispersoids uniformly distributed in the matrix to the abrading media which as a result of the resistance offered loses its sharpness and eventually breaks.

The high stress abrasive wear behaviour of the alloy and composite in the cast and aged conditions were carried out at two loads of 3 and $5 \mathrm{~N}$; the abrasive used was emery paper of 220 grit size. 


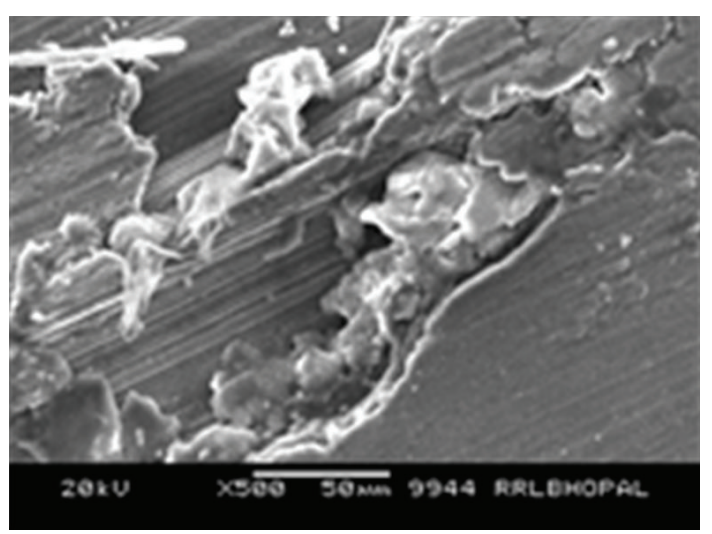

(a)

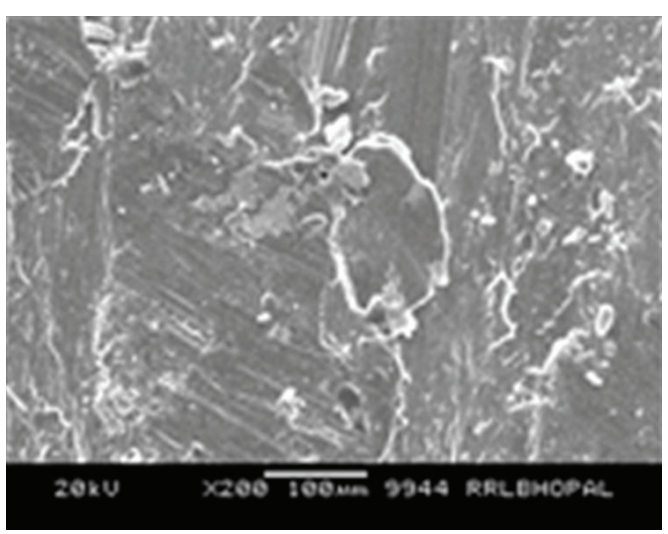

(b)

Figure 12: Micrographs of seized samples.

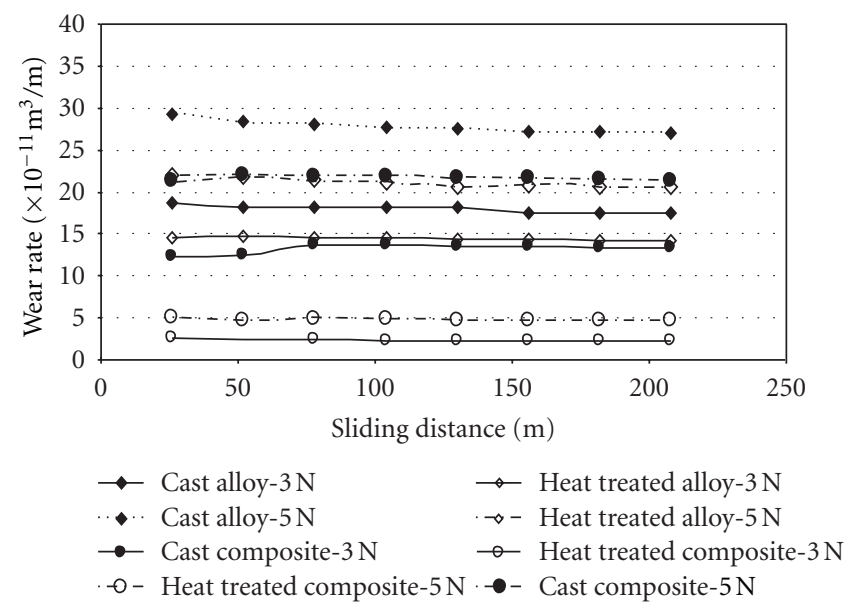

FIGURE 13: High stress abrasive wear behaviour of 2014 alloy and composite.

Composite making improves the high stress abrasive wear rate under all the experimental conditions for the 7075 series of alloys, which shows a steady rate with distance mostly in all the cases (Figure 14).

However, the high stress abrasive wear behaviour in the aged condition exhibits higher wear rates as shown in Figure 15. This could be attributed to the softening of the aged sample under loading conditions as prevalent under high stress abrasive wear conditions, which is more pronounced in the presence of abrasives. In the case of composite also, there is no beneficial effect of ageing, that is, the wear rate of the annealed composites is higher than the cast counterparts under identical experimental conditions.

3.5. Subsurface Features. The microstructural features of the longitudinal cross section of the worn pin for the 2014 alloy and composite are shown in Figure 16. In the case of cast alloy, (Figure 16(a)) a white layer is formed but the microstructural features are not well pronounced. In the case of aged alloy (Figure 16(b)), the thickness of the white layer is much less and the microstructural features are well resolved. The damaged region is also clearly seen and the region below the damaged region shows a tendency of plastic deformation in the sliding direction (Figure 16(c)). The subsurface features of the cast and aged composite (Figure 17) shows similar features as in the case of alloy. The plastic deformation appears to have been stopped/reversed on encountering the reinforced $\mathrm{SiC}$ particulates. The damaged region as measured by the thickness beneath the subsurface is also appreciably lesser in the case of composites as compared to the alloy. The subsurface of the aged composite shows cracking till a substantial depth from the affected region (Figure 17(c)). This indicates that metal flow when arrested by the presence of $\mathrm{SiC}$ particulates results in stress accumulation and hence in cracking.

\section{Discussion}

The mechanism of wear is in general very complex mainly due to the number of contributing factors to material removal [19-24]. The complexity and prediction of wear to be encountered in any system is increased as in actual conditions under any mode of wear, the real area of contact between two solid surfaces compared with the apparent area of contact is invariably very small, being limited to points of contact between surface asperities. The load applied to the surfaces will be transferred through these points of contact and the localised forces can be very large. The material intrinsic surface properties such as hardness, strength, ductility, work hardening, and so forth are very important factors for wear resistance, but other factors like surface finish, lubrication, load, speed, corrosion, temperature and properties of the opposing surface, and so forth are equally important. The gradual removal of a material(s) from one or both surfaces in contact increases the clearance between the surfaces. This spatial freedom induces a vibration that often leads to fatigue failures of machinery components. In many cases, the presence of a wear product during the process of wear like the wear debris even in small amounts 


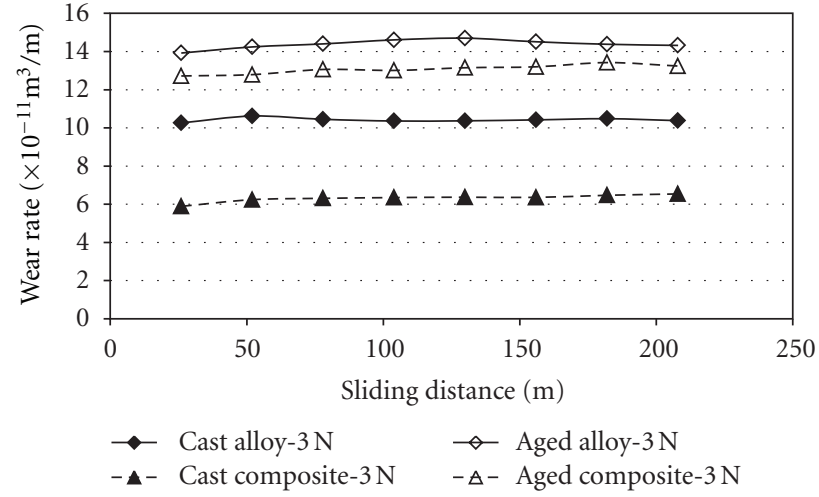

(a)

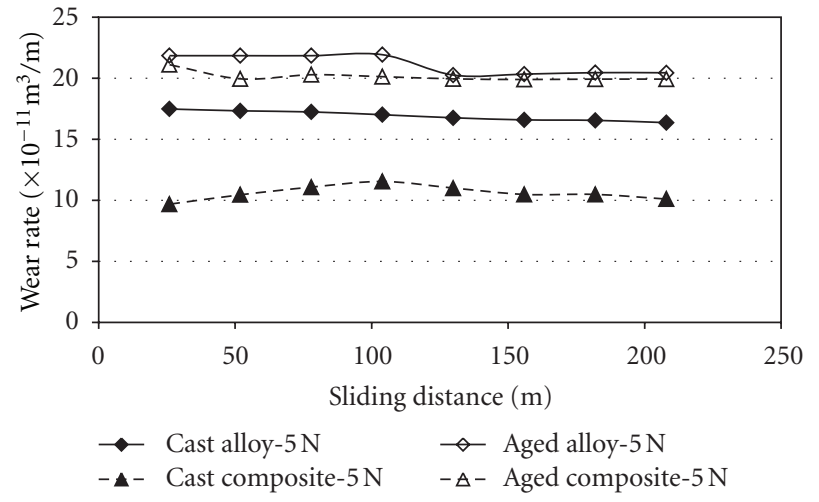

(b)

FIGURE 14: High stress abrasive wear rate behaviour between cast and aged conditions for 7075 alloy system (a) alloy (b) composite.

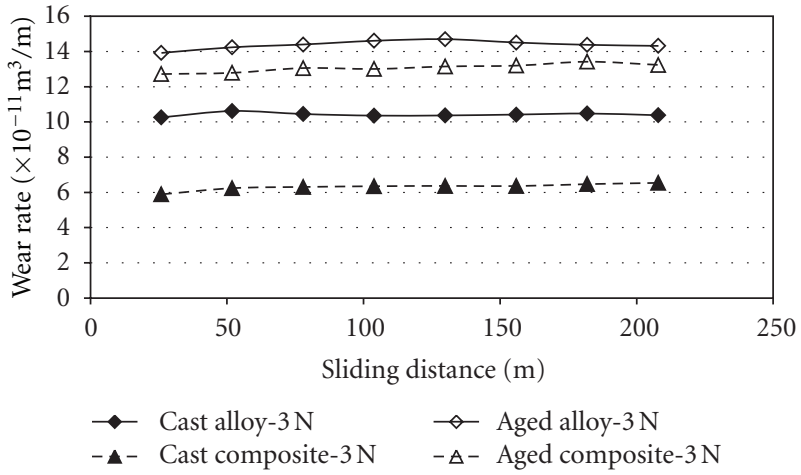

(a)

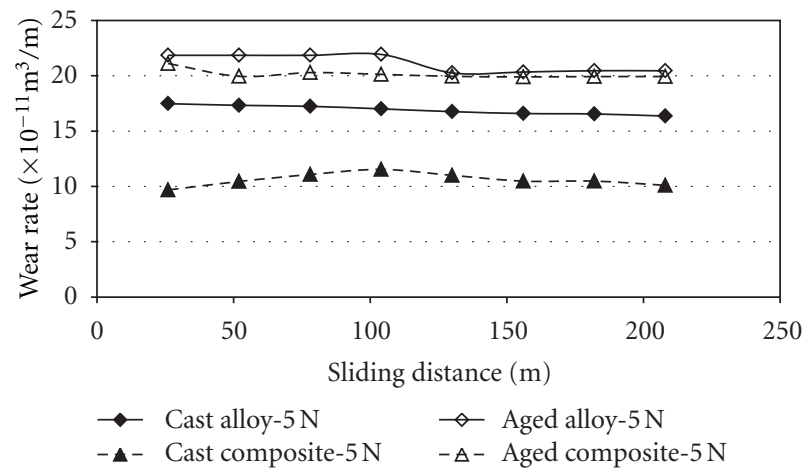

(b)

FIGURE 15: High stress abrasive wear rate behaviour between alloy and composite (a) load $=3 \mathrm{~N}$ (b) load $=5 \mathrm{~N}$.

can cause catastrophe and even before the breakdown affects the performance of the parts undergoing wear. Thus, even if wear cannot be done away with, the wear debris during wear should be attempted to be minimised either by removing them or designing of materials that have better wear resistant properties.

Under conditions where mild sliding wear conditions prevail, in this case at higher speeds, wear is generated by fracture and removal of the oxide layer which is formed in aluminium alloys, as a result of continued sliding action (Figure 18(a)). Higher material loss is associated with micro ploughing action, observed under low speed conditions at both the loads (Figure 18(b)). It may be said that the benefits of composite formation is seen from the improved wear resistance as observed in shallower wear tracks under the same conditions when compared with the alloy (Figure 18(c)); also the beneficial effects of ageing is evident in all the cases (alloy and composite) under identical experimental conditions. The improved wear resistance in composites is mainly attributed to the effective resistance of the $\mathrm{SiC}$ particle to penetration, grinding and cutting by the ceramic particulates. When the particle sizes are small, matrix strengthening of the particles as well as wear resistance of the particles contributes to improving the wear resistance (inverse of wear rate). Ageing improves the toughness of the material hence inspite of lower hardness the wear rate is decreased (improved wear resistance).

There are many possible wear mechanisms: adhesion, abrasion, erosion, and so on. Generally, more than a single mechanism occurs at the same time both in actual operation of machines and even in experimental conditions, this cannot be completely ruled out. However, there is always a primary mechanism that determines the material removal rate. Whenever there is a possibility of abrasive wear, it is the most important problem to be solved. The wear rate of abrasive wear is at least one to two orders of magnitude larger than those of other mechanisms. The abrasive wear mechanism is basically the same as machining, grinding, polishing, or lapping that we use for shaping materials. Two body abrasive wear occurs when one surface (usually harder than the second) cuts material away from the second, although this mechanism very often changes to three body abrasion as the wear debris then acts as an abrasive between the two surfaces. Abrasives act as in grinding where the 


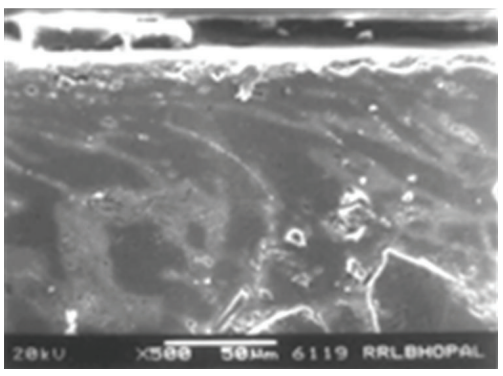

(a)

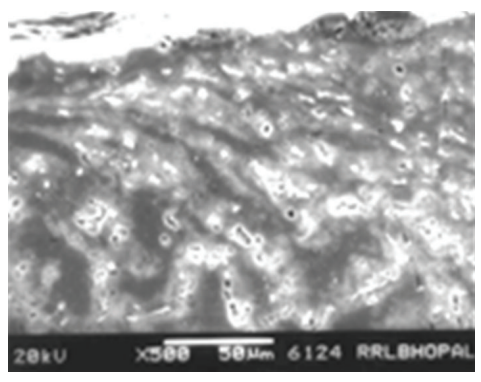

(b)

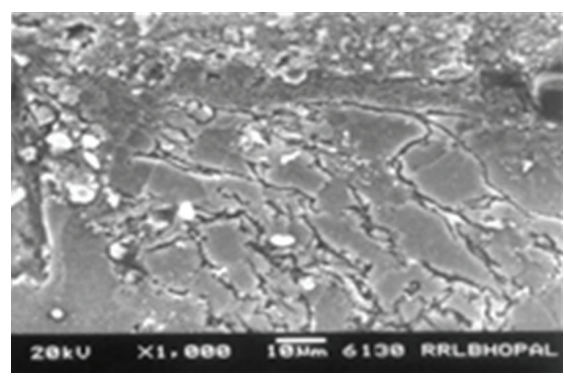

(c)

Figure 16: Subsurface features of 2014 alloy. (a) Cast alloy showing white layer formation (b) aged alloy showing well resolved microstructural features and thin white layer (c) damaged region show a tendency of plastic deformation in the sliding direction.

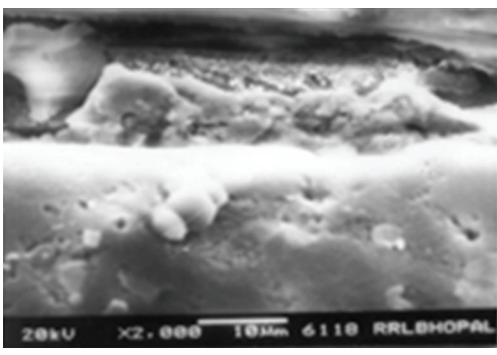

(a)

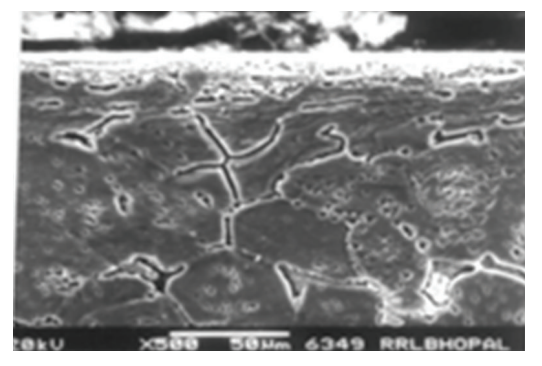

(b)

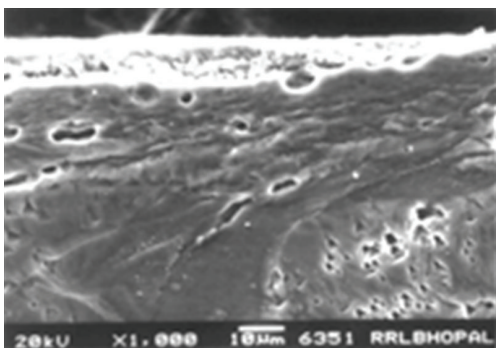

(c)

FIGURE 17: Subsurface features of 2014 composite. (a) cast composite (b) aged composite showing behaviour of plastic deformation on encountering the reinforced $\mathrm{SiC}$ particulates (c) aged composite show cracking till a substantial depth from the affected region.

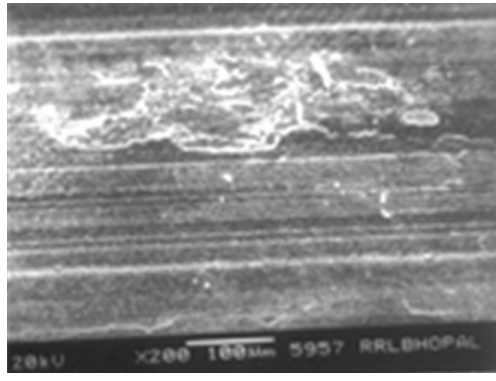

(a)

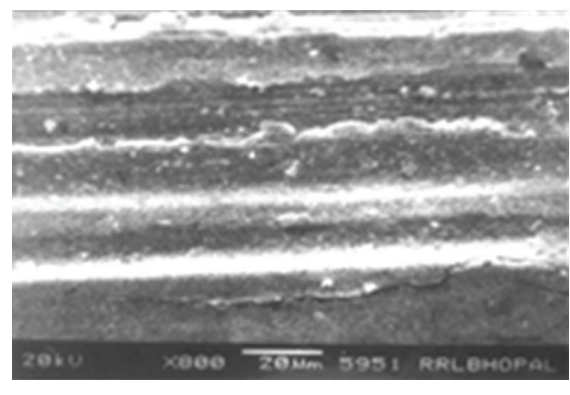

(b)

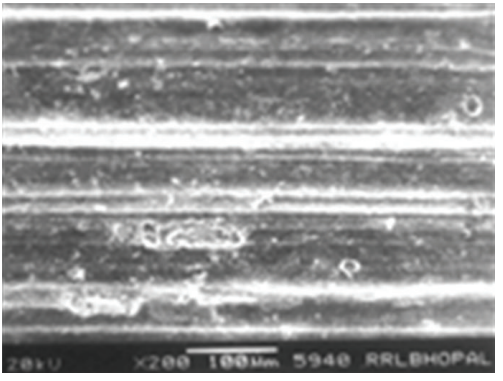

(c)

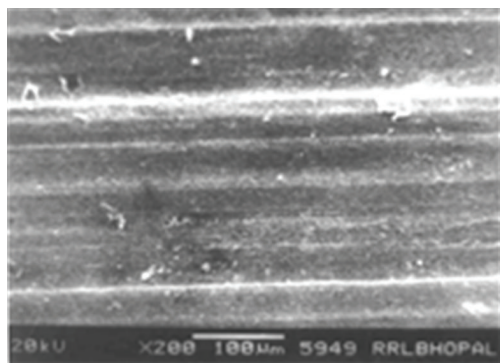

(d)

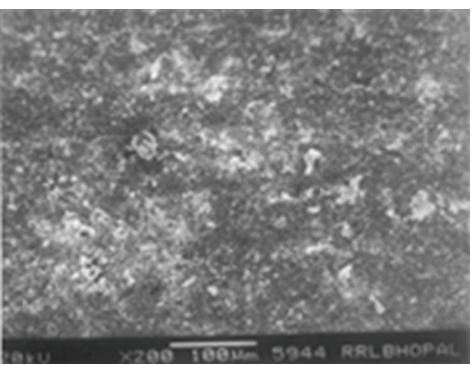

(e)

FIGURE 18: Worn surfaces under different experimental conditions (a) cast alloy tested at low load (b) cast alloy tested at higher load (c) aged alloy tested at higher load (d) cast composite under same experimental conditions as in "a" (e) aged composite tested at higher load. 
abrasive is fixed relative to one surface or as in lapping where the abrasive tumbles producing a series of indentations as opposed to a scratch.

Simple predictive models developed for wear loss in abrasive wear of ductile metals, assuming that mass loss resulted from repeated indentation from the corners and asperities of angular particles rolling across the surface of the wear specimen does not hold good under most, as it does not take into account wear through sliding and cutting by the particles. Examination of wear surfaces suggested that individual particles traversed the wear surface in a mixed slide (scratch)-roll manner. Under most of the test conditions examined, sliding/cutting was the dominant metal removal mechanism, although wear by indentation was generally not insignificant. Abrasive wear happens when the particular material is being removed from one surface, by another harder material, as a result, hard particles of the debris between the two surfaces are formed. The terms scratching, gouging, or scoring are used depending on the degree of abrasive wear. In simple words, the harder material scratches the softer material. There are 2 conditions in which abrasive wear occurs. The 2 body abrasion and 3 body abrasion. In the former, the harder surface rubs the other. Examples of these include mechanical grinding, cutting, and machining. The latter involves a third body. This third body is generally a small particle of abrasive between the 2 softer rubbing surfaces. Microscopically, abrasive wear causes asperities of the harder surface to press into the softer surface, with plastic flow of the softer surface formed around the harder asperities. These result in "micro ploughing" and "micro cracking" where tangential motion is imposed [24, 25].

Abrasive wear resistance of a monolithic material is usually poor as it offers very little resistance to the harder surface sliding against it during wear modes classified as abrasive. Making multiphase material cannot improve the abrasive wear resistance of such materials. The technique is by introducing a secondary phase(s) into the matrix material; hence, composites have invariably shown much better wear resistant properties under abrasive conditions over the base alloys. The mechanism of material removal during two body abrasive wear of Al-alloy composites with $\mathrm{SiC}$ dispersoids are primarily cutting and plowing, which lead to formation of continuous wear grooves. The advantage of making composites can be seen from the significantly lower wear rate in them as compared to the base alloy; in the former the $\mathrm{SiC}$ particles act as protrusions over the surface and protect the matrix from wear (Figures 18(a), 18(d), 18(b), and 18(e)). But at higher applied load, coarser abrasive size, and larger sliding distances, some of the $\mathrm{SiC}$ particles get fractured into fine particles and scooped off from the wear surface leading to a higher wear rate and since the abrasives are now loose and if not removed from the surface the behaviour changes to that of three body abrasion. The subsurface studies show severe plastic deformation and finally formation of a mechanically mixed layer (MML) over the plastically deformed zone. The MML gets fractured during the wear process and finally removed by the formation of lateral and transverse cracking. The cracks are generally initiated at the interface of MML and the plastically deformed zone and propagate along the weaker region in MML [26].

This is a scraping, grinding mechanism that rubs away metal surfaces and can be caused by the scouring action of the abrasives in the abrasive paper. The scouring action is a result of both abrasion and sliding and can be seen microscopically as scratches under low load and small sliding distance but as the load and/or sliding distance increases, the scratches become continuous and parallel grooves are observed and later the depth increases. The abrasive paper is degraded and the loose abrasives fall into the created grooves; however, these are removed when fresh emery paper is used after a certain traversal distance. Where lubricants are used, the oil serves as a bed for accumulation of abrasives and thus needs to be changed at regular intervals for smooth operation, else the contaminated oil at times results in more wear loss that under dry/unlubricated conditions.

A number of wear models and mathematical expressions of wear rate have been predicted; however for reliable predictions, it is better to conduct fresh experiments as the number of variables and their effects on the wear rate are always sketchy and depend on experimental conditions [27].

\section{Conclusions}

Al-alloy based composites were thought of about a quarter of a century back when the possibilities of improvement in Alalloys by the then conventional methods of heat treatment and microstructural modification had reached its limit. Composites took a lead as compared to the other processes when the cost and ease of fabrication were compared. The other methods changed track and chose for itself different areas of application and Al-based metal matrix composites (AMMCs) remained as the most potential candidate to be researched on for making engineering components viably. When the question of viability arose, from the different methods adopted for making AMMCs the liquid metallurgy route stood ahead due to its ease of fabrication; although the other routes were more efficient regarding property attainment and microstructural features, still the ease of fabrication added to the cost economics made the liquid metallurgy route a competitive and viable method. Worldwide research in the area of AMMCs established beyond doubt the advantages of these materials over the base alloy. The demands moved ahead and engineering components were demanded from AMMCs. However, engineering products could not make a dent when this technology was adopted. One of the properties that showed marked improvement was the wear resistance, the contributing factor being the better wear resistance of the dispersoids. However, attaining uniform dispersion was an area of specialisation.

The present paper highlights the improvements in different types of wear normally encountered by engineering components during service and the improvements attained in them by making composites through the liquid metallurgy route and also ageing. Two alloy systems generally used by the engineering sector amongst the different aluminium 
based alloys have been reported in the present study. The interesting point to be noted is that an otherwise nonwear resistant alloy like the 7075 system also exhibits significant improvement in wear resistance when composites are fabricated from them. This opens up additional avenues for this alloy system.

The wear mechanism has been explained and conditions where composites can perform better than alloys have been arrived at. Engineering components where the working conditions are similar to the conditions under which experiments have been conducted can be fabricated from the composites, and it is expected to be performed with ease and be better than the presently used alloys.

\section{References}

[1] M. S. Zedalis, P. S. Cilman, and S. K. Das, "High temperature aluminum-base composites," in High Performance Composites for the 1990's, S. D. Das et al., Ed., pp. 61-81, The Metallurgy Society of AIME, Warrendale, Pa, USA, 1990.

[2] P. K. Rohatgi, S. Das, and T. K. Dan, "Cast Al-graphite particle composites, a potential engineering material," Journal of the Institution of Engineers, vol. 67, no. 2, pp. 77-83, 1987.

[3] P. K. Rohatgi, S. Das, and R. Asthana, "Science, technology and industrial potential of cast metal ceramic particle composites," in Materials Science and Technology in the Future, pp. 123-184, CSIR, Bhopal, India, 1985.

[4] Engineered Materials Handbook: Composites, vol. 1, ASM International, Materials Park, Ohio, USA, 1989.

[5] M. K. Surappa, "Aluminium metal matrix composites: challenges and opportunities," Sadhana, vol. 28, no. 1-2, pp. 319 334, 2003.

[6] U. Hecht and S. Rex, "On the transition from pushing to engulfment during directional solidification of the particlereinforced aluminum-based metal-matrix composite $2014+$ $10 \mathrm{Vol} \mathrm{Pct} \mathrm{Al}_{2} \mathrm{O}_{3}$," Metallurgical and Materials Transactions A, vol. 28, no. 13, pp. 867-874, 1997.

[7] R. Asthana, "Reinforced cast metals: part I Solidification microstructure," Journal of Materials Science, vol. 33, no. 7, pp. 1679-1698, 1998.

[8] C. P. Hong, H. F. Shen, and I. S. Cho, "Prevention of macrosegregation in squeeze casting of an $\mathrm{Al}-4.5$ wt pet $\mathrm{Cu}$ alloy," Metallurgical and Materials Transactions A, vol. 29, no. 1, pp. 339-349, 1998.

[9] L. H. Chen and D. A. Rigney, "Transfer during unlubricated sliding wear of selected metal systems," Wear, vol. 105, no. 1, pp. 47-61, 1985.

[10] R. L. Deuis, C. Subramanian, and J. M. Yellup, "Abrasive wear of aluminium composites-a review," Wear, vol. 201, no. 1-2, pp. 132-144, 1996.

[11] F. M. Hosking, F. F. Portillo, R. Wunderlin, and R. Mehrabian, "Composites of aluminium alloys: fabrication and wear behaviour," Journal of Materials Science, vol. 17, no. 2, pp. 477498, 1982.

[12] S. Turenne, Y. Châtigny, D. Simard, S. Caron, and J. Masounave, "The effect of abrasive particle size on the slurry erosion resistance of particulate-reinforced aluminium alloy," Wear, vol. 141, no. 1, pp. 147-158, 1990.

[13] K. H. Z. Gahr, "Wear by hard particles," Tribology International, vol. 31, no. 10, pp. 587-596, 1998.

[14] P. J. Blau, "Fifty years of research on the wear of metals," Tribology International, vol. 30, no. 5, pp. 321-331, 1997.
[15] A. T. Alpas and J. D. Embury, "Sliding and abrasive wear behaviour of an aluminum (2014)-SiC particle reinforced composite," Scripta Metallurgica et Materiala, vol. 24, no. 5, pp. 931-935, 1990.

[16] D. Rupa and M. Humaira, "High stress abrasive wear behaviour of Al-2014 alloy and its SiC composite," International Journal of Microstructure and Materials Properties, vol. 3, no. 2-3, 2008.

[17] R. Dasgupta, H. Meenai, and S. Das, "Age hardening of Al 201alloy and 2014-SiC composites," Journal of Materials Science Letters, vol. 22, no. 5, pp. 391-394, 2003.

[18] D. Rupa, "The stretch, limit and path forward for particle reinforced metal matrix composites of 7075 Al-Alloys," Engineering, vol. 2, no. 4, pp. 237-256, 2010.

[19] S. Das, D. P. Mondal, S. Sawla, and S. Dixit, "High stress abrasive wear mechanism of LM13-SiC composite under varying experimental conditions," Metallurgical and Materials Transactions A, vol. 33, no. 9, pp. 3031-3044, 2002.

[20] M. S. Bingley and S. Schnee, "A study of the mechanisms of abrasive wear for ductile metals under wet and dry three-body conditions," Wear, vol. 258, no. 1-4, pp. 50-61, 2005.

[21] K. Kato, "Classification of wear mechanisms/models," Proceedings of the Institution of Mechanical Engineers J, vol. 216, no. 6, pp. 349-356, 2002.

[22] X. F. Zhang, G. Y. Lee, D. Chen, R. O. Ritchie, and L. C. De Jonghe, "Abrasive wear behavior of heat-treated ABC-silicon carbide," Journal of the American Ceramic Society, vol. 86, no. 8, pp. 1370-1378, 2003.

[23] R. I. Trezona, D. N. Allsopp, and I. M. Hutchings, "Transitions between two-body and three-body abrasive wear: influence of test conditions in the microscale abrasive wear test," Wear, vol. 225-229, no. I, pp. 205-214, 1999.

[24] J. A. Williams and A. M. Hyncica, "Mechanisms of abrasive wear in lubricated contacts," Wear, vol. 152, no. 1, pp. 57-74, 1992.

[25] F. M. Hosking, F. F. Portillo, R. Wunderlin, and R. Mehrabian, "Composites of aluminium alloys: fabrication and wear behaviour," Journal of Materials Science, vol. 17, no. 2, pp. 477498, 1982.

[26] B. Venkataraman and G. Sundararajan, "Correlation between the characteristics of the mechanically mixed layer and wear behaviour of aluminium, Al-7075 alloy and Al-MMCs," Wear, vol. 245, no. 1-2, pp. 22-38, 2000.

[27] Y. L. Gun, C. K. H. Dharan, and R. O. Ritchie, "A physicallybased abrasive wear model for composite materials," Wear, vol. 252, pp. 322-331, 2002. 

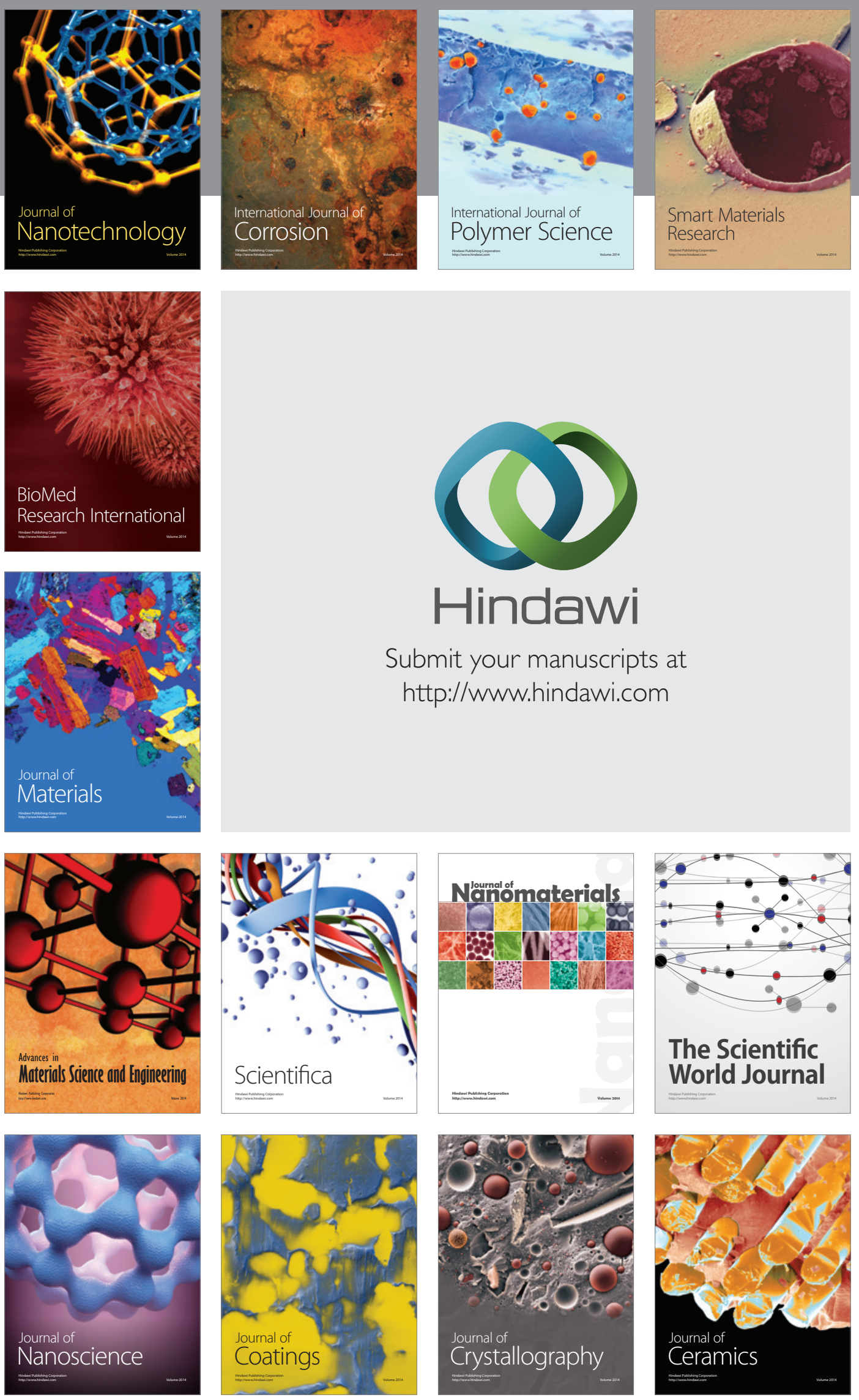

The Scientific World Journal

Submit your manuscripts at

http://www.hindawi.com

\section{World Journal}

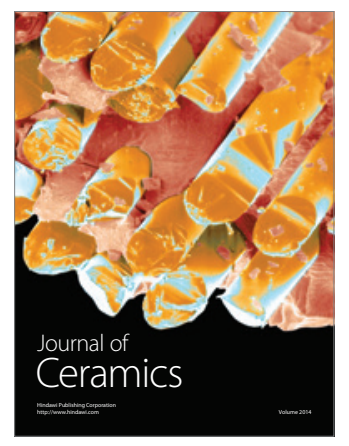

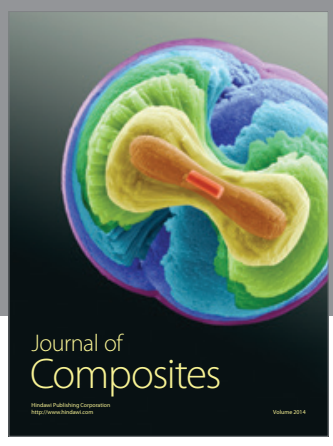
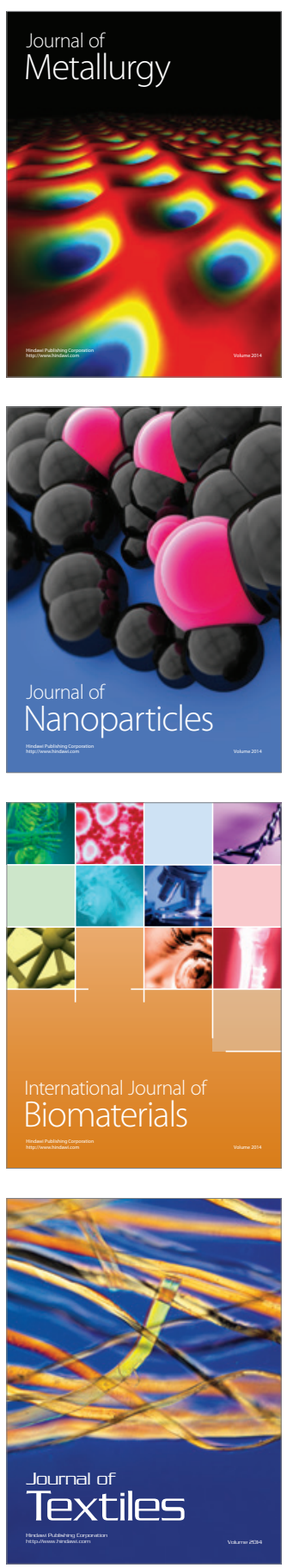